\title{
Análise microbiológica de provadores de maquiagens
}

\author{
Microbiological analysis of makeup testes
}

\author{
Análisis microbiológico de probadores de maquillajes
}

Cynthya Hellen Costa Macedo ${ }^{1 *}$, Kályta Andrely Barbosa Nascimento Pereira1, Bruna Luisa Figueiredo Pierote ${ }^{2}$, Kelly Maria Rêgo da Silva ${ }^{3}$, João Paulo da Silva Sampaio², Antônio Luiz Gomes Junior $^{2}$, Adriana Saraiva dos Reis².

\section{RESUMO}

Objetivo: Verificar a presença de microrganismos e identificar as espécies encontradas em provadores de maquiagens presentes em lojas da zona sudeste da cidade de Teresina-Piauí. Métodos: Trata-se de um estudo observacional transversal, conduzido a partir da análise de dezenove (19) amostras de provadores de maquiagens. Os cosméticos foram avaliados através do método de esgotamento por estrias nos meios de cultura Ágar Sangue, Macconkey, Cetrimide e Sabouraud, confirmadas através das análises macroscópicas, microscópica e testes bioquímicos. Resultados: Das dezenove (19) amostras analisadas, três (3) apresentaram crescimento microbiológico, verificando a presença das espécies bacterianas Klebsiella $s p$, Kocuria kristinae e fúngica Aspergillus niger. As amostras analisadas não apresentam sérios riscos para pessoas saudáveis, entretanto podem gerar patologias em indivíduos com o sistema imunológico fragilizado. Conclusão: $\mathrm{Em}$ algumas das amostras foram encontrados a presença de microrganismos. $O$ ato de compartilhar tais produtos pode impactar em riscos à saúde do usuário, necessitando assim um maior cuidado com a utilização desses cosméticos.

Palavras-chave: Análise microbiológica, Cosméticos, Controle de qualidade.

\begin{abstract}
Objective: Verify the presence of microorganisms and identify the species found in makeup tasters present in stores in the southeast of the city of Teresina-Piauí. Methods: This is a cross-sectional observational study, conducted from the analysis of nineteen makeup tester samples. The cosmetics were evaluated by striae depletion method in the blood, macconkey and cetrimide agar culture media, and sabouraud, confirmed by macroscopic, microscopic and biochemical tests. Results: Of the nineteen samples analyzed, three showed microbiological growth, verifying the presence of the species klebsiella sp, Kocuria Kristinae and Aspergillus niger. The samples do not present serious risks in healthy people, however can generate pathologies in individuals with weakened immune systems. Conclusion: In some of the samples were found the presence of microorganisms. Sharing such products can impact user health risks, thus requiring greater care with the use of these cosmetics.
\end{abstract}

Keywords: Microbiological analysis, Cosmetics, Quality control.

\section{RESUMEN}

Objetivo: Verificar la presencia de microorganismos e identificar las especies econtradas en probadores de maquillaje presentes en tiendas en el sureste de la ciudad de Teresina-Piauí. Métodos: Este es un estudio observacional transversal, realizado a partir del análisis de diecinueve muestras de probadores de maquillaje. Los cosméticos fueron evaluados por el método de agotamiento de estrías en los medios de cultivo de sangre, macconkey y agar cetrimida, y sabouraud, confirmado por pruebas macroscópicas, microscópicas y bioquímicas. Resultados: De las diecinueve muestras analizadas, tres mostraron crecimiento microbiológico, verificando la presencia de las especies klebsiella sp, Kocuria Kristinae y Aspergillus niger. Las muestras no

\footnotetext{
${ }^{1}$ Centro Universitário (UNNOVAFAPI), Teresina-PI. *E-mail: cynthyamacedo16@gmail.com

2 Universidade Federal do Piauí (UFPI), Teresina-PI.

${ }^{3}$ Instituto Educacional de Santa Catarina (INCURSOS), Jaraguá do Sul-SC.
} 
presentan riesgos serios en personas sanas, sin embargo, puede generar patologías en individuos con sistemas inmunes debilitados. Conclusión: En algunas de las muestras se encontró la presencia de microorganismos. Compartir dichos productos puede afectar los riesgos para la salud del usuario, lo que requiere un mayor cuidado con el uso de estos cosméticos.

Palabras clave: Análisis microbiológico, Cosmética, Control de calidad.

\section{INTRODUÇÃO}

O controle da contaminação microbiana de fórmulas magistrais, dentre elas os cosméticos, é de fundamental importância na Saúde Pública. Um grande número de microrganismos com potencial patogênico pode estar presente nos produtos cosméticos, como vírus, bactérias e fungos, e, portanto, o ato de compartilhar tais produtos pode impactar em riscos à saúde do usuário (MOTA, et al., 2017). Cosméticos são produtos constituídos de substâncias naturais ou sintéticas que possuem o objetivo de proteger e/ou embelezar diferentes partes do corpo humano, a exemplo dos que são destinados a maquiagem, como bases, batons, sombras, pó facial, máscaras de cílios e outros (RITO, et al., 2012). De acordo com a Associação Brasileira da Indústria de Higiene Pessoal, Perfumaria e Cosméticos (ABIHPEC), o Brasil possui um dos maiores números de consumidores de cosméticos no mundo, principalmente quando o assunto é beleza, ocupando a quarta posição no ranking mundial (ABIHPEC, 2019).

O aumento da procura por cosméticos de qualidade não se limita ao público feminino. Percebe-se que os homens também constituem uma parcela significativa no mercado consumidor e, dentro desse segmento, as indústrias de cosméticos buscam constante crescimento com o desenvolvimento de novos produtos que satisfaçam o desejo de beleza dos consumidores. Com isso, as indústrias têm a necessidade de um controle rígido desde a formulação química desses produtos até a escolha correta de um conservante (ARAÚJO RS, et al., 2017; ARAÚJO RS, et al., 2018). Dessa forma, com o intuito de reduzir os riscos microbiológicos, uma etapa importante durante a produção dos cosméticos é a escolha dos conservantes, que visam garantir a eficácia e a segurança do produto final.

Estes fatores são assegurados pela Resolução da Diretoria Colegiada (RDC) № 481, de 23 de setembro de 1999, que determina os valores permitidos de microrganismos patogênicos e não patogênicos em produtos não estéreis (BRASIL, 1999). De acordo com a Agência Americana Food and Drug Administration (FDA), compartilhar ou trocar cosméticos, principalmente maquiagens, com outras pessoas pode causar graves danos à saúde humana. Portanto, levando em consideração os testadores dos produtos disponíveis ao público em lojas de varejo, o risco é ainda maior, em virtude da grande quantidade de pessoas que fazem uso do mesmo produto e não possuem informações objetivas sobre a eficácia dos conservantes após o uso destes cosméticos (BENVENUTTI, et al., 2016).

Considerando a grande proporção que as maquiagens vêm tomando no mercado nas últimas décadas, juntamente com a necessidade de garantir segurança ao consumidor, este estudo tem por objetivo verificar a presença de microrganismos e identificar as espécies encontradas nos provadores de maquiagens presentes em lojas da zona Sudeste da cidade de Teresina - Piauí.

\section{MÉTODOS}

Trata-se de um estudo observacional transversal de análise microbiológica de cosméticos de uso público realizado na cidade de Teresina- PI. Para este estudo, foram selecionados aleatoriamente cosméticos para maquiagens adquiridas no período de outubro de 2019, em estabelecimentos comerciais de produtos de beleza na zona Sudeste da cidade de Teresina-PI. Foram analisadas dezenove (19) amostras: quatro (4) amostras de bases líquidas, quatro (4) amostras de sombras em pó, quatro (4) amostras de batons, três (3) amostras de pós faciais, duas (2) amostras de máscaras de cílios e duas (2) amostras de pó para sobrancelhas.

As metodologias aplicadas para análises foram adaptadas e baseadas em parâmetros determinados pela RDC 481 de 23 de setembro de 1999, que dispõe sobre o controle microbiológico de produtos cosméticos. 
Os procedimentos microbiológicos foram realizados dentro da capela de fluxo laminar desinfetada de acordo com procedimentos padrões para evitar contaminações, todos os insumos utilizados eram estéreis e todos os materiais manipulados foram previamente esterilizados em autoclave por 15 minutos a $121^{\circ} \mathrm{C}, 1 \mathrm{~atm}$.

\section{Preparo das amostras}

O preparo de amostras foi realizado a partir da diluição destas em água micelar. O objetivo inicial da diluição foi neutralizar os conservantes presentes nos cosméticos que impedem o crescimento bacteriano evitando, assim, possíveis interferentes na análise. O diluidor empregado neste estudo foi uma solução utilizada para limpeza facial que possui a habilidade de dissolver a maioria dos cosméticos faciais comercializados atualmente. Neste trabalho foi empregada a proporção $1 / 99$, onde utilizou-se $100 \mathrm{mg}$ de amostra para $9,9 \mathrm{ml}$ do diluidor. Por se tratar de um produto com gordura em sua composição, portanto, de difícil diluição, nas amostras de batons foram adicionadas duas gotas de Dimetilsulfóxido (DMSO), um composto mundialmente utilizado como solvente orgânico polar e aprótico.

Além das amostras de batom, também foram adicionadas duas gotas de DMSO nas amostras de máscaras de cílios, pois estas possuíam a característica de serem resistentes a água, não sendo, desta forma, diluídas em água micelar. Após a pesagem, foram acrescentadas $1 / 3$ do volume do diluente nas amostras, sendo posteriormente agitadas sob ação mecânica em aparelho vortex durante 60 segundos. Todas as amostras foram fundidas em banho-maria a $37^{\circ} \mathrm{C}$ por 10 minutos, acrescentando o volume total de diluente à temperatura ambiente ao final do tempo. Para todos os meios utilizados foi realizado um semeio de controle do diluidor com a mesma técnica de semeadura utilizada para as amostras.

\section{Pesquisa de patógenos}

A pesquisa de patógenos foi realizada através do método de esgotamento por estrias em ágar sangue, meio enriquecido que favorece o crescimento de diversas espécies bacterianas, empregado no isolamento de microrganismos não fastidiosos. As placas de Petri foram incubadas na estufa bacteriológicas a $35 \pm 2{ }^{\circ} \mathrm{C}$ por 24 horas. Para confirmação de espécies sugestivas foram realizadas análises macroscópicas das colônias (cor, aspecto, odor, brilho, borda, tamanho, convexa ou côncava, hemólise), microscópicas (forma, afinidade ao corante e arranjo) e provas bioquímicas em meio rugai modificado e Vitek® para auxiliar na identificação dos agentes desenvolvidos.

\section{Pesquisa de coliformes totais e pseudomonas aeruginosas}

A partir das amostras diluídas foi realizada a pesquisa de coliformes totais e termotolerantes através do esgotamento em estrias em Ágar Macconkey, meio de cultura destinado para o isolamento de bactérias Gram negativas, e na verificação da fermentação da lactose, os quais foram incubados de forma invertida na estufa bacteriológica a $35 \pm 2{ }^{\circ} \mathrm{C}$ por 48 horas.

A pesquisa de Pseudomonas aeruginosa foi desenvolvida a partir da técnica de esgotamento em estrias em Ágar Cetrimide, um meio seletivo e diferencial para o gênero Pseudomonas, recomendado para a pesquisa de Pseudomonas aeruginosa em cosméticos e para análise de microbiológica de produtos farmacêuticos não estéreis. As placas foram incubadas de forma invertidas por 48 horas a $35 \pm 2{ }^{\circ} \mathrm{C}$.

\section{Pesquisa de Fungos}

Para a pesquisa de fungos, foi realizada a técnica de esgotamento através do cultivo em Ágar SabouraudDextrose (SBD) com Clorafenicol, meio com nutrientes que favorecem o crescimento de uma variedade de fungos leveduriformes e filamentosos, além de inibir o crescimento de bactérias. As placas de Petri foram posteriormente incubadas em estufa bacteriológica por 15 dias a $35 \pm 2{ }^{\circ} \mathrm{C}$, com observações diárias. Para confirmação das espécies sugestivas, foram realizadas a técnica de microcultivo com o meio Ágar batata dextrose (BDA), que visa cultivar fungos com estruturas íntegras, facilitando assim a identificação. As placas foram incubadas por 96 horas a $35 \pm 2{ }^{\circ} \mathrm{C}$.

A identificação da espécie foi realizada com auxílio do "Atlas de micologia médica" dos autores MARTINS, MELO E HEINS-VACCARI, $1^{\circ}$ ed. de 2004. Observou-se primeiramente as características macromorforlógicas da colônia, onde o fungo apresentou seu desenvolvimento em menos de sete dias com aspecto de camurça branca e coberta com uma densa camada de conidias negras. 
$\mathrm{Na}$ análise micromorfológico foram visualizadas as seguintes estruturas: conidióforos longos de paredes lisas e hialinas, com coloração escura na região da vesícula, apresentou as cabeças da conidiais globulosas de coloração marrom-escuros, com fiálides bisseriadas.

\section{RESULTADOS E DISCUSSÃO}

A avaliação da qualidade microbiana tem fator decisivo no controle de qualidade dos cosméticos, de onde se faz necessário o uso de conservantes que impedem a proliferação de diferentes microrganismos (BRASIL, 2013). O controle de qualidade integra-se às boas práticas de fabricação (BPF), que são exigências cumpridas pelos fabricantes de cosméticos para garantir a segurança e qualidades dos mesmos (BENVENUTTI, et al., 2016). De acordo com a Resolução 481 da Agência Nacional de Vigilância Sanitária (ANVISA), os cosméticos podem ser classificados em tipo I, produtos de uso infantil que entram em contato com mucosas e/ou olhos, ou tipo II que são os demais cosméticos passíveis de contaminação microbiológica, que devem estar de acordo com os padrões de qualidade microbiana, com a finalidade de proteção de risco para o consumidor (BRASIL, 1999).

Para analisar a qualidade microbiológica de um cosmético é fundamental atestar inexistência de microrganismos causadores de patologias aos usuários, além de definir a quantidade de carga microbiológica como fungos e bactérias viável existente no produto (DE OLIVEIRA, et al., 2016). Segundo a Resolução da Diretoria Colegiada ํo. 481, de 23 de setembro de 1999, os cosméticos do tipo I não devem conter mais do que $5 \times 10^{2} \mathrm{UFC} / \mathrm{g}$ (Unidade Formadora de Colônia/ grama), e o tipo II $5 \times 10^{3} \mathrm{UFC} / \mathrm{g}$, sendo esses dados utilizados para classificar produtos apropriados para uso ou impróprios para o consumo, sendo um recurso de segurança para os consumidores (TONIN, et al., 2007).

Foram analisadas 19 (dezenove) amostras de cosméticos de uso coletivo sendo eles, três (3) amostras de bases, duas (2) amostras de corretivos, três (3) amostras de sombra, quatro (4) amostras de batons, três (3) amostras de pós faciais, duas (2) amostras de máscaras de cílios e duas (2) amostras de pó para sobrancelhas. Essas amostras foram cultivadas em diferentes meios de culturas como o ágar Sangue, o ágar MacConkey, o ágar Cetrimide e o ágar Sabouraud, que são os meios de cultura mais utilizados para identificação de diferentes patógenos, como mostra a Tabela 1.

Tabela 1 - Resultado da análise microbiológica de provadores de maquiagens.

\begin{tabular}{|c|c|c|}
\hline Amostras & Contagem de bactérias (UFC/g) & Microrganismos \\
\hline Controle Negativo & $<10$ UFC/g & Ausente \\
\hline $1-$ Base & $<10$ UFC/g & Ausente \\
\hline 2 - Base & $<10$ UFC/g & Ausente \\
\hline 3 - Base & $<10$ UFC/g & Ausente \\
\hline 4 - Corretivo & $<10 \mathrm{UFC} / \mathrm{g}$ & Ausente \\
\hline 5 - Corretivo & $<10$ UFC/g & Ausente \\
\hline 6 - Pó facial & $>10 \mathrm{UFC} / \mathrm{g}$ & Aspergillus niger \\
\hline 7 - Pó facial & $<10$ UFC/g & Ausente \\
\hline 8 - Pó facial & $<10$ UFC/g & Ausente \\
\hline 9 - Batom & $>10 \mathrm{UFC} / \mathrm{g}$ & Kocuria Kristinae \\
\hline $10-$ Batom & $<10$ UFC/g & Ausente \\
\hline 11 - Batom & $<10$ UFC/g & Ausente \\
\hline $12-$ Batom & $<10$ UFC/g & Ausente \\
\hline 13 - Sombra & $<10$ UFC/g & Ausente \\
\hline $14-$ Sombra & $<10$ UFC/g & Ausente \\
\hline $15-$ Sombra & $<10$ UFC/g & Ausente \\
\hline 16 - Máscara de cílios & $>10 \mathrm{UFC} / \mathrm{g}$ & Klebsiella sp. \\
\hline 17 - Máscara de cílios & $<10$ UFC/g & Ausente \\
\hline 18 - Pó de sobrancelha & $<10$ UFC/g & Ausente \\
\hline 19 - Pó de sobrancelha & $<10$ UFC/g & Ausente \\
\hline
\end{tabular}

Legenda: UFC: unidade formadora de colônia. Fonte: Macedo CHC, et al., 2019. 
Para a contagem microbiológica foi registrado como $<10 \mathrm{UFC} / \mathrm{g}$ toda amostra cujo resultado demonstrouse ausente, ou seja, não apresentou crescimento bacteriano. Para resultados positivos, realizou-se a contagem de unidades formadoras de colônias. Assim, as amostras de bases, de pó para sobrancelhas, de sombra, e de corretivos analisadas não apresentaram crescimento microbiológico.

Analisando os resultados obtidos com base nas normas da RDC no 481/1999, as amostras seis (6) (pó facial), nove (9) (batom) e dezesseis (16) (máscara de cílios) são consideradas impróprias para o uso por conter número maior que $10 \mathrm{UFC/g}$, e as demais (16 amostras) são seguras para utilização sugerindo que, na maior parte desses produtos, os conservantes cumpriram com seu objetivo de preservar o cosmético da propagação de microrganismos durante seu uso.

Figura 1 - Análises realizadas na amostra 9, com crescimento em ágar Sangue (1) e morfologia microscópica das colônias (2).

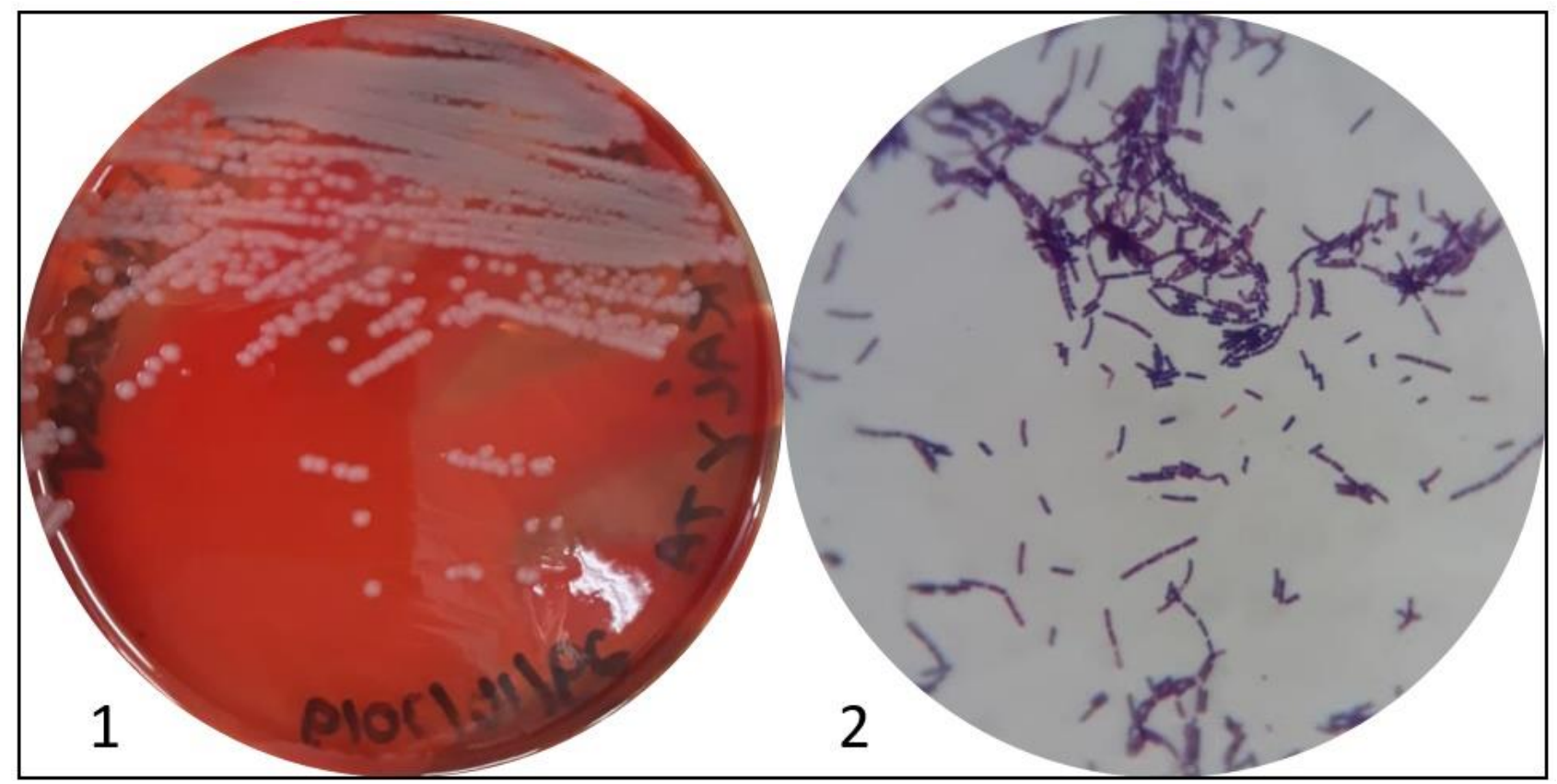

Fonte: Macedo CHC, et al., 2020.

Com base nas informações da tabela 1, a amostra nove (9) referente a um batom, apresentou crescimento bacteriano no meio Ágar Sangue (Figura 1), apresentando colônias pequenas cremosas não hemolíticas, de coloração esbranquiçadas. A análise microscópica demonstrou bacilos gram positivos observado na figura 1.2 , onde posteriormente foram realizados testes em laboratório externo com o equipamento Vitek® 2, um sistema automatizado que garante a excelência na identificação dos microrganismos de amostras clínicas e testes de susceptibilidade aos antimicrobianos (TSA).

O sistema Vitek® opera por meio de cartões com código de barras, assegurando uma completa rastreabilidade e minimizando os riscos de erros de transcrição. Com a realização das análises, foi identificado a espécie Kocuria Kristinae, uma bactéria geralmente não patogênica, amplamente distribuída na natureza e frequentemente encontrada na flora normal da pele e mucosa (HASSAN, et al., 2016). Infecções relacionadas a Kocuria Kristinae são incomuns em humanos saudáveis, entretanto foram relacionadas como causadores de infecções em pacientes imunocomprometidos com doenças subjacentes, estando, também, associadas com infecções do trato urinário, endocardite, peritonite e colecistite (LAKSHMIKANTHA, et al., 2015).

Em 1981, em Atlanta, foram avaliadas 1345 amostras de sombras de uso para clientes, de diferentes marcas, sendo $67 \%$ destas, ou seja, a maior parte das sombras possuía contaminação por patógenos do tipo Staphylococcus, Micrococcus, Corynebacterium, Acinetobacter, Bacillus e Moraxella (DAWSON NL e REINHARDT DJ, 1981). 
Um estudo realizado por Tran TT e Hitchins AD (1994) nos Estados Unidos, destacou que de 2892 amostras de diferentes cosméticos, dentre eles, batons, bases e corretivos, 50\% dessas estavam contaminadas, dentre das quais $5 \%$ tinha um número considerado inadmissível para uso, em que $2 \%$ estavam contaminados por bactérias oportunistas. Uma outra análise realizada por Benvenutti AS, et al. (2016) na cidade de Curitiba - PR, demonstrou que de 15 amostras de diferentes cosméticos (sombras, blush, batons, máscaras de cílios e pós faciais), $20 \%$ apresentavam contaminações por Staphylococcus coagulase positiva, das quais $13,3 \%$ foram consideradas inapropriadas para uso.

Figura 2 - Análises realizadas na amostra 16, com crescimento em Ágar Sangue (1) e Ágar Macconkey (2), morfologia microscópica em bacilos gram negativos (3) e teste bioquímicos em meio Rugai modificado.

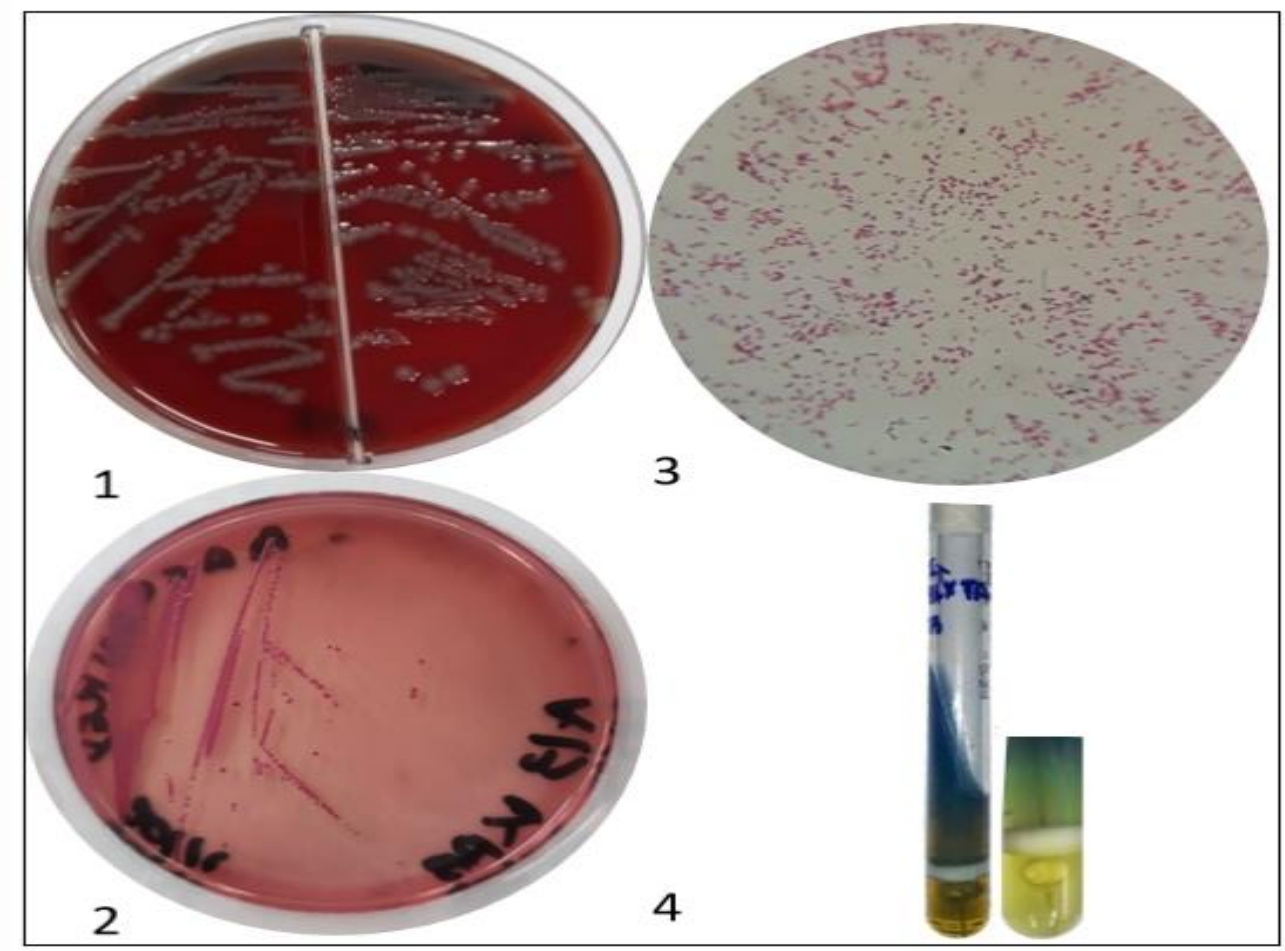

Fonte: Macedo CHC, et al., 2020.

Conforme observado na tabela 1 , a amostra 16 referente a uma máscara de cílios apresentou crescimento bacteriano no meio ágar Sangue e ágar Macconkey. Foi observado as características macroscópicas onde apresentava colônias grandes e arredondadas de coloração rosa (Ágar Macconkey), de consistência mucoide, brilhantes, com bordas lisas, sem a produção de hemólise, através da análise microscópica observou-se bacilos gram negativos, e os testes bioquímicos demonstraram bactérias imóveis produtoras de gás e fermentadoras de glicose, com ausência na produção do indol, lisina e sacarose (Figura 1) a partir dessas características foi determinado como o gênero Klebsiella sp, uma bactéria amplamente encontrada no meio ambiente (água, solo e plantas) e flora normal do trato gastrointestinal dos animais, incluindo os humanos.

Em humanos, as bactérias do gênero Klebsiella constantemente estão associadas a infecções nasocomiais, representando alta morbimortalidade em pessoas (PEREIRA SCL e VANETTI MCD, 2015). Segundo Hazen TH, et al. (2014) a Klebsiella pneumoniae é a espécie de maior patogenicidade pertencente a esse gênero e são frequentemente relacionadas a infecções do trato urinário, pneumonia, gastroenterite, meningite e septicemia.

Em um estudo feito por Pack LD, et al. (2008) para avaliar o crescimento microbiano em 39 amostras de máscaras de cílios, foi comprovado o crescimento bacteriano em doze (12) amostras, e isoladas Staphylococcus epidermidis. Da mesma maneira, o autor Accacio LL, et al. (2015) analisou cinquenta e sete (57) amostras de máscaras de cílios utilizadas em salões de beleza e verificou que 17,5\% (10) das amostras se apresentaram contaminadas com Staphylococcus epidermidis. 
Figura 3 - Análises realizadas na amostra 6, com crescimento em Ágar Sabouraud (1) e morfologia microscópica após microcultivo (2).

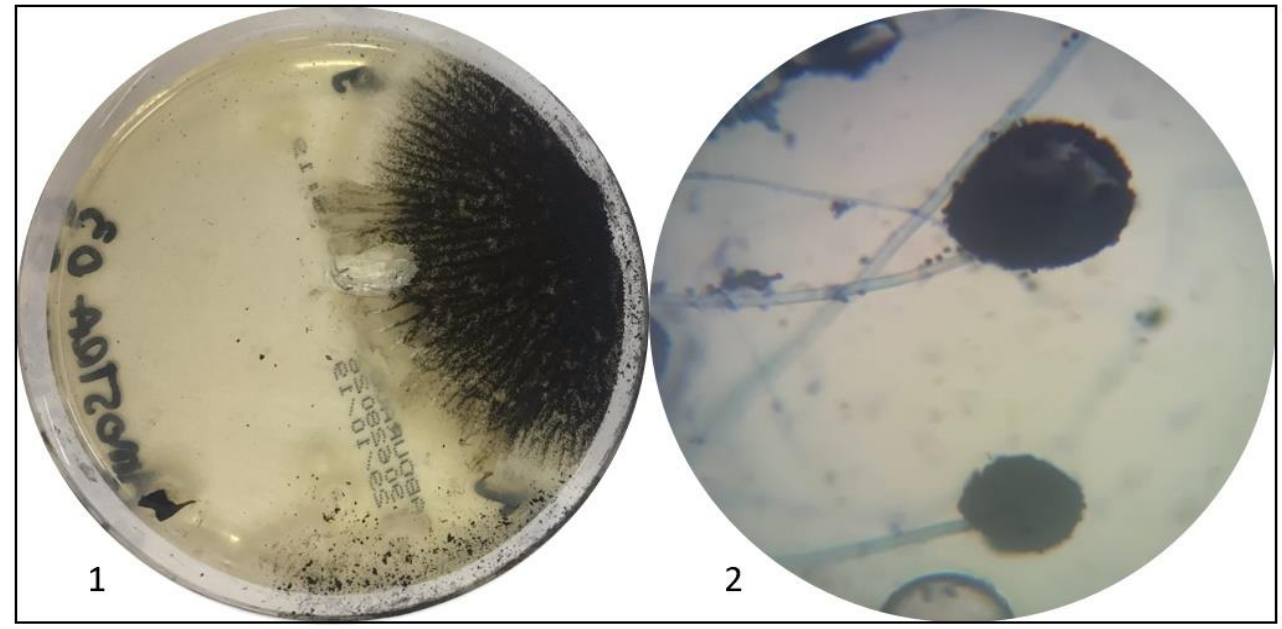

Fonte: Macedo CHC, et al., 2020.

Analisando as informações da tabela 1, das 19 amostras estudadas, apenas a amostra 6, referente a um pó facial apresentou contaminação por fungos, tornando-se $5 \%$ do total inapropriadas para uso. Na figura 3.1 observa-se crescimento em meio Ágar Sabouroud, de colônias enegrecidas de textura cremosa da superfície, com aspecto de camurça e pesada cobertura de conídios pretos centrais semelhantes a pimenta do reino ou café. A observação microscópica pela técnica de microcultivo, demonstrou a presença de hifas hialinas, septos muito próximos, com conídios grandes e pretos, e vesículas globosas com fiálides bisseriadas (3.2). Através das características obtidas foi identificado como sendo Aspergillus níger, uma espécie de fungo que é capaz de provocar reações alérgicas e infecções oportunistas no humano, principalmente em indivíduos imudeprimidos. Esta espécie possui a característica de crescer em diferentes ambientes, sendo capaz de provocar biotransformação de compostos, modificando produtos no geral, como os cosméticos, geando riscos à saúde dos usuários.

Mundialmente o Aspergillus níger possui grande importância na indústria mundial, pois verificou-se que essa espécie é capaz de produzir ácido cítrico (um dos ácidos mais utilizados na indústria) e enzimas como a lactase, utilizada na produção de doces, sendo geralmente reconhecido como seguro (GRAS) pela Food and Drug Administration (FDA) dos Estados Unidos da América (AFONSO SOM, 2015). No estudo realizado por Brandão R, et al. (2015) no estado de Goiás, foram avaliadas oito (8) amostras de bases cosméticas faciais de diferentes marcas, sendo $2,5 \%$ destas positivas para fungos filamentosos e leveduras, ou seja, uma pequena parcela das amostras analisadas apresentou-se fora do limite de $3 \times 10^{2} \mathrm{UFC} / \mathrm{g}$ estabelecido pela ANVISA.

No trabalho de Da Silva JCPDA, et al. (2017), foram analisadas trinta (30) amostras de maquiagens e de assessórios (pincéis e esponjas) utilizadas por maquiadores profissionais onde $56,67 \%$ se apresentaram positivas para espécies de Staphylococcus aureus, Staphylococcus epidermidis, Staphylococcus saprophyticus e Bacillus $s p$. Os assessórios foi o que apresentou maior contaminação seguido das sombras e em todas amostras que se mostram positivas encontrou-se $S$. epidermidis. Assim como na análise realizada por Foppa VC, el al. (2018), em que foram examinados materiais utilizados em salões de beleza por maquiadores profissionais e que 30\% das dez (10) amostras apresentaram contaminação por Staphyloccocus $s p$. As espécies de Staphyloccocus encontradas foram a Staphyloccocus epidermidis. Em contrapartida, um estudo desenvolvido por Araújo RS, et al. (2017/2018) em Belo Horizonte -MG demonstrou que das amostras analisadas (base líquida, base sólida em bastão, batom sólido em bastão e sombra em pó) após três meses de uso nenhuma apresentou contaminação por fungos e bactérias. Os microrganismos identificados nas amostras podem estar associados as principais fontes de contaminações microbiológicas durante o processo produtivo ou de exposição, como ambiente, equipamentos, matéria-prima utilizada, contato físico a indivíduos e tempo de exposição, ou a combinação desses fatores, que geram perda de qualidade dos produtos. 
Os cosméticos, principalmente as maquiagens, costumam não apresentar características sensoriais tão evidentes de contaminação, nem costumam ocasionar danos a indivíduos saudáveis, o que pode, por muitas vezes, passar por despercebidas aos usuários, mas em organismos previamente debilitados podem ocasionar sérios riscos à saúde (RODRIGUES AP, et al., 2018).

Os cosméticos são particularmente suscetíveis a contaminações microbianas em diferentes etapas que vão desde o seu desenvolvimento até a sua utilização, pois contêm os nutrientes básicos para crescimento das colônias como substâncias orgânicas que são fontes de carbono, de sais minerais e de água, representando um meio de fácil acesso para proliferação de bactérias e fungos. A ação de microrganismos sob os cosméticos pode desencadear várias reações de transformação ou de degradação, como a oxidação do etanol formando ácido acético e a decomposição da ureia em amônia requerendo, portanto, maior cuidado no compartilhamento e uso (MARTINS ALA e REZENDE C, 2017).

\section{CONCLUSÃO}

Das amostras analisadas no presente estudo, concluiu-se que 15,79\% apresentam crescimento de microrganismos em valores acima do preconizado pela RDC 481/1999, verificando a presença das espécies Klebsiella sp, Kocuria kristinae e Aspergillus niger. Os achados apontam para a necessidade de maior cuidado com a utilização de cosméticos, especialmente com as práticas de troca e compartilhamento destes produtos, uma vez que podem apresentar microrganismos com potencial causador de doenças a seus usuários, principalmente em indivíduos imunodeprimidos. Este trabalho corrobora com estudos na área e sugere a necessidade de maior rigor no controle de qualidade das indústrias cosméticas e cuidado no cumprimento das Boas Práticas de Manipulação para a prevenção de riscos à saúde dos consumidores e à população em geral.

\section{REFERÊNCIAS}

1. ABIHPEC. Associação Brasileira da Indústria de Higiene Pessoal, Perfumaria e Cosméticos 2019.

2. ACCACIO LL, et al. PRESENÇA DE STAPHYLOCOCCUS AUREUS E STAPHYLOCOCCUS EPIDERMIDIS EM MÁSCARAS DE CÍLIOS UTILIZADAS EM SALÕES DE BELEZA NA CIDADE DE SARANDI-PR. n. 9, p. 4-8. 2015.

3. AFONSO SOM. Aspergillus niger: sua utilização na indústria farmacêutica. Dissertação (Mestrado em Ciências Farmacêuticas) - Instituto Superior de Ciências da Saúde Egas Moniz. Instituto Universitário Egas Moniz, Portugual, 2015.

4. ARAÚJO, R.S. et al. Avaliação de contaminantes microbiológicos em produtos cosméticos. Revista Iniciação Científica, 2017/2018, 35 -39.

5. BENVENUTTI AS, et al. Avaliação da qualidade microbiológica de maquiagens de uso coletivo. Arquivo de Ciência da Saúde UNIPAR, 2016; 20 (3), 159-163.

6. BRANDÃO R, et al. Análise microbiológica de bases cosméticas faciais. Revista Eletrônica Faculdade Montes Belos, 2015; 8 (1).

7. BRASIL, Ministério da Saúde. Agência Nacional de Vigilância Sanitária. RDC no 481, de 23 de setembro de 1999, estabelece parâmetros para Controle Microbiológico de Produtos de Higiene Pessoal, Cosméticos e Perfumes. Diário Oficial da União, Brasília, DF, 6 de outubro de 1999.

8. BRASIL. Resolução de Diretoria Colegiada no 48 , de 25 de outubro de 2013, aprova o Regulamento Técnico de Boas Práticas de Fabricação para Produtos de Higiene Pessoal, Cosméticos e Perfumes, e dá outras providências. Órgão emissor: ANVISA - Agência Nacional de Vigilância Sanitária.

9. DA SILVA JCDA; CAMARGO, B. CONTAMINATION OF MAKEUP FOR COLLECTIVE USE BY STAPHYLOCOCCUS AUREUS AND STAPHYLOCOCCUS EPIDERMIDIS. Simp.TCC/Sem.IC.2017(12)

10. DAWSON, N.L.; REINHARDT, D.J. Microbial flora of inuse, display eye shadow testers and bacterial challenges of unused eye shadows. Applied and environmental microbiology, 1981; 42 (2), 297-302.

11. DE OLIVEIRA LS, et al. Análise da contaminação microbiológica de diferentes dentifrícios. Rev Odontol UNESP, 2016 $45(2) ; 85-89$.

12. DINIZ AMM, SANTOS RMC. Escherichia coli e Klebsiella spp. ESBL em Hospital Universitário, na cidade de ManausAM. Revista de epidemiologia e controle de infecção, 2019; 9 (2), 129-133.

13. FOPPA VC, et al. AVALIAÇÃO DA BIOSSEGURANÇA EM ESTABELECIMENTOS DE APLICAÇÃO DE MAQUIAGEM. Infarma-Ciências Farmacêuticas, v. 30, n. 3, p. 178-184, 2018.

14. HASSAN, RM, et al. Bacteremia caused by Kocuria kristinae from Egypt: Are there more? A case report and review of the literature. Case reports in infectious diseases, 2016, 2016.

15. HAZEN TH. et al. Characterization of Klebsiella sp. strain 10982, a colonizer of humans that contains novel antibiotic resistance alleles and exhibits genetic similarities to plant and clinical Klebsiella isolates. Antimicrobial agents and chemotherapy, 2014; 58 (4), 1879-1888. 
16. LAKSHMIKANTHA, M, et al. Is Kocuria kristinae an upcoming pathogen. International Journal of Current Microbiology and Applied Sciences, 2015; 4 (4), 885-889.

17. MARTINS ALA, REZENDE C. Análise microbiológica de cosméticos labiais. ANAIS-UNIC-Congresso de Iniciação Científica-UNIFEV. 2017; 9-10.

18. MOTA VAM, et al. O controle da contaminação microbiológica de produtos magistrais. Revista Brasileira Multidisciplinar, 2017; 20 (1), 33-48.

19. PACK LD, et al. Microbial contamination associated with mascara use: Optometry. J. Amer. Optometric Ass, $2008 ; 79$ (10), $587-593$.

20. PEREIRA SCL, VANETTI MCD. Potential virulence of Klebsiella sp. isolates from enteral diets. Brazilian Journal of Medical and Biological Research, 2015; 48 (9), 782-789.

21. RITO PN, et al. Avaliação dos aspectos do controle da qualidade de produtos cosméticos comercializados no Brasil analisados pelo Instituto Nacional de Controle de Qualidade em Saúde. Revista do Instituto Adolfo Lutz, 2012 ; 71 (3); 557-565.

22. RODRIGUES AP, et al. Os danos à saúde acarretados pelo mau uso das maquiagens. Revista Científica Unibalsas, 2018; 9 (2).

23. TONIN FZ, et al. Avaliação microbiológica de produtos cosméticos manipulados em farmácias do Planalto Médio, RS. Infarma-Ciências Farmacêuticas, 2007; 19 (5/8): 117-119.

24. TRAN TT, HITCHINS AD. Microbial survey of shareduse cosmetic test kits available to the public. J. Ind. Microbiology, $1994 ; 13: 389-391$ 